\title{
PENERAPAN BRANCH AND BOUND UNTUK ALTERNATIF PEMILIHAN RUTE TERPENDEK DALAM PENGIRIMAN DOKUMEN PADA PERUSAHAAN FREIGHT FORWARDER
}

\author{
Made Irma Dwiputranti 1), Vinny Meidiana Putri 2) \\ 1)Program Diploma D3 Logistik Bisnis ,Politeknik Pos Indonesia \\ Email:madeirma@poltekpos.ac.id \\ 2)Program Diploma D3 Logistik Bisnis ,Politeknik Pos Indonesia \\ Email:Vinnymp170598@gmail..com
}

\begin{abstract}
Abstrak
Perkembangan bisnis logistik yang tersebar di seluruh dunia memicu persaingan antara bisnis logistik mereka berusaha memenuhi harapan pelanggan dengan cara memberikan pelayanan yang lebih memuaskan daripada yang dilakukan oleh pesaing. Transportasi juga sangat berperan penting dalam perkembangan industri logistik terutama dalam bidang jasa pengiriman barang karena dalam menjalankan jasa pengiriman barang dibutuhkan moda transortasi untuk memindahkan barang sampai ke tempat tujuan. Oleh karena itu, untuk menjalankan jasa transportasi atau kegiatan distribusi dibutuhkan biaya dan waktu yang besar sehingga efisiensi dibidang transportasi sangat dibutuhkan untuk mengurangi total biaya dan waktu. Pada perusahaan Freight Forwarder terdapat suatu departemen ekspor dan impor dimana didalamnya terdapat tim Delivery Order yang bertugas untuk mengurus dokumen hingga DO selesai dan dikirim. Messenger yang bertugas untuk mengambil DO ke pelayaran tidak dapat mengambil dokumen tepat waktu karena adanya keterlambatan dan penyebabnya utamanya adalah rute tidak optimal yang harus dilalui oleh messenger dalam pengambilan DO ke pelayaran. Hasil penelitian menunjukkan bahwa perusahaan dapat menggunakan alternatif jalur terpendek dimana menghasilkan jarak tempuh dari $91,6 \mathrm{~km}$ menjadi 76,13 km. Metode ini dapat di gunakan untuk menyelesaikan permasalahan penentuan jalur terpendek yang digunakan untuk meminimalkan waktu distribusi dengan cara mencari jarak dan rute terdekat.
\end{abstract}

\section{Kata Kunci: Delivery Order, Transportasi, Travelling Salesmen Problem, Branch and Bound}

\section{PENDAHULUAN}

Transportasi adalah suatu usaha memindahkan, menggerakkan, mengangkut, atau mengalihkan suatu objek dari suatu tempat ketempat lain yang dimana tempat lain ini objek tersebut lebih bermanfaat atau dapat digunakan untuk tujuan-tujuan tertentu. Dengan demikian dapat disimpulkan bahwa transportasi adalah aktivitas pemindahan barang dan penumpang dari titik asal ke tempat tujuan dengan menggunakan alat angkut sehingga terlihat dua unsur penting yaitu pemindahan atau pergerakan (movement) dan secara fisik mengubah tempat atau lokasi dari suatu barang atau penupang ke tempat atau lokasi yang lain. PT. Leschaco Logistic Indonesia adalah salah satu perusahaan freight forwarder yang bergerak dibidang jasa ekspor impor serta penyedia jasa logistik. Freight forwarder, freight berarti muatan atau pengangkutan, dan forwarder berati agen expeditur atau kantor ekspedisi. Freight forwarder adalah usaha yang ditujukan untuk mengurus semua kegiatan yang diperlukan bagi terlaksananya pengiriman dan penerimaan muatan melalui transportasi darat, laut maupun udara yang meliputi kegiatan antara lain : penerimaan, penyimpanan, sortasi, pengemasan, penimbunan muatan, pengurusan, penyelesaian dan penerbitan dokumen angkutan, perhitungan biaya angkutan klaim, asuransi, dan penyelesaian tagihan yang berkaitan dengan pengiriman muatan sampai diterima oleh consignee. PT.Leshaco Logistic Indonesia memiliki Tim Delivery Order (DO) bertugas mengurus dokumen hingga DO bisa di release.Tim DO menerima informasi dari PIC 
Impor bahwa ada barang impor milik customer yang telah dikirim dari negara eksportir dan akan diproses untuk pengambilan DO nya ke agen freight forwarder atau pelayaran. Pada proses pengirimannya terdapat 3 orang yang masing-masing memegang shipment dari customer yang berbeda. kegiatan pengambilan DO tersebut dimulai sejak messenger mengambil dokumen pendukung yang harus dibawa dari kantor $\mathrm{HO}$ di Pondok Indah Office Tower pada pukul 9.00 WIB dan pengambilan DO harus bisa terambil semua maksimal hingga jam 16.30 WIB saat kantor agen/pelayaran telah tutup dalam melayani pengambilan DO. Jika ada dokumen DO yang tidak bisa diambil pada hari itu, maka dokumen tersebut ditunda, dan akan diambil pada keesokan harinya, terdapat 50 hingga 70 DO perhari yang harus diambil oleh 5 messenger, dan masingmasing messenger membawa jumlah DO yang berbeda tergantung banyaknya dokumen dari customer, dan pengambilan DO dilakukan menggunakan cara multidrop, yaitu pengambilan dokumen DO dilakukan oleh satu messenger menggunakan satu kendaraan ke beberapa tempat tujuan dalam satu kali proses pengambilan dokumen. Koordinator dari tim DO menentukan jalur untuk ambil DO dan jalur yang diberikan berubah-ubah setiap harinya, tergantung pada dokumen yang diberikan oleh PIC impor kepada tim DO, dan PIC impor pun juga tergantung atas permintaan dari customer, Sehingga belum adanya rute tetap yang harus dilalui oleh messenger, karena rutenya berdasarkan permintaan dari para customer.Dokumen DO yang tertunda dan tidak bisa diambil oleh para messenger pada hari yang telah ditentukan, dianggap sebagai keterlambatan. Metode Branch and Bound sering digunakan untuk menyelesaikan suatu permasalahan program integer karena hasil yang diperoleh dalam penyelesaian optimal lebih teliti dan lebih baik dari metode lain. Metode ini dikatakan lebih teliti dan lebih baik dari metode lain karena hasil optimal yang diperoleh biasanya lebih dari satu sehingga penulis dapat menentukan mana hasil yang paling optimal dari hasil-hasil yang telah diperoleh tersebut. Pada penelitian sebelumnya metode ini juga bisa dipakai untuk Penentuan rute yang kurang optimal dalam mendistribusikan produk sepatu ke seluruh store di Indonesia dari gudang tunggal yang dimiliki PT. X yang menyebabkan tingginya biaya distribusi dalam satu hari di perusahaan tersebut. Pada penelitian ini Metode Branch and Bound memiliki tujuan untuk menentukan jalur terpendek yang bisa dilalui oleh messenger untuk mengambil dokumen DO agar lebih hemat waktu sehingga dokumen DO yang diambil bisa terambil semuanya dan bisa langsung lebih cepat dibawa ke Tanjung Priok. Tujuannya agar barang bisa lebih cepat keluar dari pelabuhan sehingga dapat meminimasi dwelling time, hemat biaya bahan bakar, dan tenaga bagi para messenger yang mengambil DO.

\section{METODE PENELITIAN}

Metode yang digunakan untuk memecahkan permasalahan ini yaitu metode Travelling Salesmen Problem model Branch and Bound yaitu untuk menentukan jarak terpendek sehingga menghasilkan waktu tempuh yang optimal yaitu dengan tahapan sebagai berikut :

1. Menyiapkan data yang akan diolah.

2. Menentukan rute kunjungan Menentukan rute kunjungan berdasarkan jadwal yang telah diberikan oleh koordinator tim DO untuk pengambilan dokumen DO yang dilakukan oleh messenger. Pengambilan dokumen DO menggunakan sistem multidrop dan penulis menentukan pengukuran jarak antar agen $\mathrm{A}$ ke agen $\mathrm{B}$ sama dengan jarak dari agen $\mathrm{B}$ ke agen A sehingga matriks jarak ini termasuk matriks symmetric.

3. Membuat graf rute yang mungkin dilalui Jadwal pengambilan dokumen ke setiap agen akan dibuat graf dan menentukan rute yang mungkin dilalui para messenger pada setiap kali messenger mengambil dokumen DO. Rute yang dibuat tidak boleh melalui jalan yang sudah dilalui dari titik awal messenger berangkat hingga messenger kembali ke titik awal lagi.

4. Menghitung jarak dan waktu Jarak yang dibutuhkan untuk melakukan setiap kegiatan pengambilan dokumen DO akan dihitung dan dicari rute mana yang tercepat dengan menggunakan metode Algoritma Branch and Bound. Waktu yang dibutuhkan saat melakukan kegiatan pengambilan dokumen DO akan dilakukan reduksi sehingga menghasilkan jaringan $\mathrm{Qij}=\mathrm{Ai}+\mathrm{Bj}$. Hasil dari reduksi jaringan Qij yang terbesar akan dipilih dan digunakan untuk melakukan pinalti pada baris dan kolom yang dihasilkan dari reduksi Qij. Jika waktu tercepat belum ditemukan maka lakukan reduksi baris dan kolom lagi hingga ditemukan rute mana yang tecepat.

5. Menentukan rute tercepat Setelah proses menghitung waktu sudah selesai dan ditemukan hasil seperti pada berikut: 
Tabel 1. Contoh Tabel Hasil Algoritma Branch

\begin{tabular}{|c|c|c|}
\hline aari/Ke & $\mathbf{1}$ & $\mathbf{3}$ \\
\hline $\mathbf{2}$ & & 0 \\
\hline $\mathbf{4}$ & 0 & \\
\hline
\end{tabular}

Maka tahap selanjutnya adalah menentukan rute yang akan dilalui dan jika dilihat dari Tabel 3.1 tersebut ditemukan urutan rute 1-2, 3-4, 4-1, 2-3 yang menghasilkan sebuah rute yaitu 1-2-3-4-1. Rute tercepat yaitu dari titik awal keberagkatan pada titik 1, kemudian menuju titik 2, dari titik 2 menuju ke titik tujuan 3 kemudian menuju titik 4, dan dari titik 4 akan kembali menuju titik awal keberangkatan yaitu titik 1 . Rute tercepat telah dibuat agar tidak ada keterlambatan pada proses pengambilan dokumen DO dan untu mempersingkat waktu sehingga DO bisa segera dikirimkan ke Tanjung Priok, dan agar lebih menghemat biaya bahan bakar dengan melalui rute jarak terpendek.

6. Data telah selesai diproses dengan menggunakan metode Algoritma Branch and Bound.

\section{PEMBAHASAN}

Pengumpulan data untuk pengoptimalan waktu keberangkatan setiap messenger yang bertugas untuk mengambil DO adalah yang ke arah jalur 4 yaitu Jakarta Selatan. Pada jalur 4 ke arah Jakarta Selatan, agen pelayaran yang harus dikunjungi oleh messenger adalah sebagai berikut :

Tabel 2 Notasi Agen Pelayaran

\begin{tabular}{|l|l|c|}
\hline No. & Agen Pelayaran & Notasi \\
\hline 1. & Leschaco & A \\
\hline 2. & Macoline & B \\
\hline 3. & Transworld & C \\
\hline 4. & Maha Kargo & D \\
\hline 5. & RGA & E \\
\hline 6. & Dagmar & F \\
\hline 7. & Ecu Line & G \\
\hline 8. & Tresnamuda & H \\
\hline 9. & FM Global & I \\
\hline 10. & Forecastle & K \\
\hline 11. & Expo Freight & \\
\hline
\end{tabular}

Tabel 3 Jarak Tempuh Messenger

\begin{tabular}{|l|l|l|l|}
\hline \multicolumn{1}{|c|}{ Rute } & \multicolumn{1}{|c|}{$\begin{array}{c}\text { Jarak } \\
\text { Tempuh }\end{array}$} & Waktu Tempuh & \multicolumn{1}{c|}{$\begin{array}{c}\text { Total } \\
\text { Waktu }\end{array}$} \\
\hline $\begin{array}{l}\text { Leschaco - Macoline - } \\
\text { Transworld - Maha Kargo - }\end{array}$ & $\begin{array}{l}26,9+8,9+ \\
4,9+2,1+\end{array}$ & $\begin{array}{l}(1 / 40)=(\mathrm{x} / 96,1) \\
\text { Sehingga }\end{array}$ & Waktu \\
tempuh + \\
RGA - Dagmar - Ecu Line - & $1,5+2,4+4$ & didapatkan $\mathrm{x}$ & waktu \\
Tresnamuda - FM Global - & $+1,7+6,4+$ & (waktu tempuh & tambah \\
Forecastle - Expo Freight & $6,5+30,8=$ & adalah $\mathbf{1 4 4}$ & $(100$ menit $)$ \\
& $\mathbf{9 6 , 1 ~ k m ~}$ & menit & $=\mathbf{2 4 4}$ \\
& & & menit \\
\hline
\end{tabular}

Berdasarkan pengolahan data yang sebelumnya telah dilakukan, kemudian data diolah menggunakan metode Algoritma Branch and Bound. Tahap awal dari metode Algoritma Branch and Bound adalah mengelompokkan setiap tujuan yang akan menghasilkan sebuah rute dengan waktu optimal. Penulis melakukan perhitungan waktu optimal sesuai dengan rute yang akan dilalui oleh para messenger. Berdasarkan data tujuan yang akan dikunjungi lalu dibuat graf yang menunjukkan rute yang mungkin dilalui saat messenger melakukan pengambilan dokumen dari titik A hingga titik terakhir dan kembali lagi menuju pada titik awal. Tujuan agen pelayaran yang akan dikunjungi digambarkan pada Gambar 4 yang merupakan Graf Rute pengambilan DO dengan menggunakan notasi huruf agar lebih mudah.

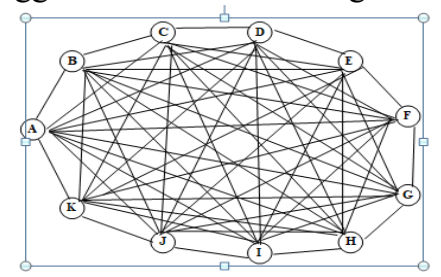

Gambar 1 Rute Pengambilan DO Jalur 4

Setelah menentukan kunjungan, dan graf yang menunjukkan alur yang harus dilalui oleh para messenger, selanjutnya adalah menghitung jarak yang harus ditempuh oleh messenger, kemudian dari jarak tersebut diolah dengan mereduksi baris dan kolom secara bergantian. Selanjutnya adalah perhitungan nilai pinalty secara bertahap sehingga diperoleh pada Tabel 4 akhir yaitu:

Tabel 4. Jarak Tempuh Antar Agen Pelayaran Pada Jalur 4 Yang Dikunjungi Messenger

\begin{tabular}{|c|c|c|c|c|c|c|c|c|c|c|c|}
\hline Dari/Ke & A & B & C & D & E & F & G & H & I & J & K \\
\hline A & & 26,9 & 35,7 & 33,5 & 24,6 & 25,8 & 33,5 & 30,4 & 32,4 & 31,5 & 30,8 \\
\hline B & 26,9 & & 8,9 & 7,6 & 7,9 & 9,1 & 12,8 & 5,1 & 6,7 & 7,3 & 4,2 \\
\hline C & 35,7 & 8,9 & & 4,9 & 1,9 & 0,18 & 2,2 & 6,2 & 4,6 & 9,1 & 6,2 \\
\hline D & 33,5 & 7,6 & 4,9 & & 2,1 & 3,3 & 1,6 & 4,3 & 0,95 & 6,6 & 4,6 \\
\hline E & 24,6 & 7,9 & 1,9 & 2,1 & & 1,5 & 0,95 & 4,9 & 3,1 & 7,8 & 5 \\
\hline F & 25,8 & 9,1 & 0,18 & 3,3 & 1,5 & & 2,4 & 6,1 & 4,5 & 9 & 6,2 \\
\hline G & 33,5 & 12,8 & 2,2 & 1,6 & 0,95 & 2,4 & & 4 & 3,4 & 6,9 & 4 \\
\hline H & 30,4 & 5,1 & 6,2 & 4,3 & 4,9 & 6,1 & 4 & & 1,7 & 5,2 & 2,4 \\
\hline I & 32,4 & 6,7 & 4,6 & 0,95 & 3,1 & 4,5 & 3,4 & 1,7 & & 6,4 & 3,9 \\
\hline J & 31,5 & 7,3 & 9,1 & 6,6 & 7,8 & 9 & 6,9 & 5,2 & 6,4 & & 6,5 \\
\hline K & 30,8 & 4,2 & 6,2 & 4,6 & 5 & 6,2 & 4 & 2,4 & 3,9 & 6,5 & \\
\hline
\end{tabular}

Sehingga ditemukan rute sebagai berikut : Leschaco Macoline - Expo Freight - Tresnamuda - Forecastle FM Global - Maha Kargo - Ecu Line - Transwolrd Dagmar - RGA - Leschaco atau notasi rute yaitu : A 
$-\mathrm{B}-\mathrm{K}-\mathrm{H}-\mathrm{J}-\mathrm{I}-\mathrm{D}-\mathrm{G}-\mathrm{C}-\mathrm{F}-\mathrm{E}-$ A dengan jumlah jarak adalah 26,9 $\mathrm{km}+4,2 \mathrm{~km}+2,4$ $\mathrm{km}+5,2 \mathrm{~km}+6,4 \mathrm{~km}+0,95 \mathrm{~km}+1,6 \mathrm{~km}+2,2 \mathrm{~km}+$ $0,18 \mathrm{~km}+1,5 \mathrm{~km}+24,6 \mathrm{~km}=76,13 \mathrm{~km}$

\section{KESIMPULAN DAN SARAN}

Berdasarkan hasil pembahasan maka dapat ditarik kesimpulan bahwa faktor penyebab keterlambatan yang dilakukan oleh messenger dalam pengambilan dokumen DO ke agen pelayaran yaitu sebagai berikut : PIC DO baru mendapat kabar bahwa kapal yang membawa barang customer ternyata delay, sedangkan messenger telah menunggu untuk pengambilan DO. Belum adanya rute tetap yang harus dilalui messenger ketika akan melakukan pengambilan dokumen DO terutama ke arah jalur 4 daerah Jakarta Selatan. Sehingga berdasarkan hasil pengolahan data yang telah dilakukan penulis dengan menggunakan metode branch and bound didapatkan bahwa rute telah optimal dengan total jarak tempuh mengalami penurunan yaitu dari 96,1 km menjadi 76,13 km dan Untuk memperbaiki keterlambatan yang dilakukan oleh para messenger yang ditugaskan ke jalur 4 yaitu dengan menentukan rute optimal yang harus dilalui oleh para messenger.

\section{REFERENSI}

Tamba, M. 2014. Aplikasi Minimasi Biaya Transportasi Pengiriman Barang Menggunakan Vogel's Approximation Method (VAM) Studi Kasus CV. Tao Toba Indah. Jurnal Transportasi Vol.7 No.1. Diakses tanggal 2 Juli 2019

Nasution, Nur. 2008. Manajemen Transportasi. Jakarta: Ghalia Indonesia

Rosa, Windi Rayina, dkk. 2016. Penentuan Jalur Terpendek Pada Pelayanan Agen Travel Khusus Pengantaran Wilayah Semarang Berbasis Sig dengan Algorirma Branch and Bound. Jurnal Masyarakat Informatika, Vol. 4 No. 7.

Wulandari,CBK.2020.Penentuan Distribusi Menggunakan Metode Nearest Neighbors dan Metode Branch and Bound untuk meminimumkan Biaya Distribusi di PT.X. Jurnal Optimasi Teknik Industri.UNINDRA 